\title{
The study of kinetics and thermodynamics of selected pharmaceuticals and personal care products on agriculture soil
}

\author{
Shehdeh Jodeh \\ Chemistry Department, An-Najah National University, Nablus, 11347, Palestine \\ *Corresponding author at: Chemistry Department, An-Najah National University, Nablus, 11347, Palestine. \\ Tel.: +970.59.9590498; Fax: +970.9.2345982. E-mail address: sjodeh@hotmail.com (S. Jodeh).
}

\section{ARTICLE INFORMATION}

Received: 08 November 2012

Received in revised form: 19 November 2012

Accepted: 22 November 2012

Online: 31 December 2012

\section{KEYWORDS}

Soil

Slurries

Diffusion

Isotherm

Adsorption

Pharmaceuticals

\begin{abstract}
Pollution of the aquatic environment by human and veterinary waste pharmaceuticals is an increasing area of concern but little is known about their ecotoxicological effects on wildlife. In this study, three pharmaceuticals were selected (ibuprofen, amoxicillin and caffeine) as examples that are released in the environment. All of them are marketed in the Palestinian market (Pharmacies), private clinics and hospitals. The adsorption of the selected pharmaceuticals was examined by batch sorption experiments onto agriculture soil. Pharmaceuticals adsorption kinetics followed the pseudo-second-order adsorption model. Adsorption isotherms were best fitted by the Freundlich isotherm model. The " $n$ " parameters were higher than 1 and the $\mathrm{K}_{\mathrm{f}}$ values for all of them were less than 1 . High removal rates of amoxicillin and ibuprofen were achieved in acidic media $(\mathrm{pH}=1-4)$ and reached more than 88\% Except for the caffeine increased at higher $\mathrm{pH}$ and reached more than $92 \%$. The thermodynamics parameters showed that the adsorption process on soil was spontaneous and exothermic.
\end{abstract}

\section{Introduction}

In the recent years, the occurrence and the fate of pharmaceutically active compounds in the aquatic environment has been recognized as one of the emerging environmental issues that have possibly been affecting the ecological system $[1,2]$. Pharmaceutical compounds may be described as any chemical used for diagnosis, treatment, alteration or prevention of diseases [3]. Taking into account the use of thousands of pharmaceuticals types in human treatment and in agricultural sector (livestock), it's not limited the size on the negative effects that these compounds will leave on the environment, as well as high cost to eliminate or mitigate these effects. It was discovered; more than 100,000 types of chemicals are used in our everyday life either in households, industries or agriculture [4]. So, pharmaceutical pollution is one of the most modern and chemical contaminants that pose to the environment.

The pharmaceutical compounds used mainly by human and livestock are excreted in slightly transformed or even unchanged form, resulting from the body fluids (urine), or from disposing of the expired drugs, causing serious damage to the ecosystem, which is still in the beginning of the study in Palestine, that's because our conventional wastewater treatment is the primary mechanism by which pharmaceuticals introduced $[5,6]$.

According to recent research, variety of these compounds were detected in various water samples including hospitals wastewater, pharmaceutical industries, waste water treatment plant effluent, surface and ground water, this illustrated by a study entitled, (occurrence of pharmaceuticals and personal care products along the West Prong little Pigeon River in east Tennessee) [7], which pointed out the presence of concentrations of some drugs in ground water and soil. In addition to the quantities of expired medicines which are disposed of in unsafe ways, it's common to pour them down in the sink, flush them down in the toilet, or throwing them in the trash, without attention to their risks through landfills leachates that may eventually reach to ground water.

Despite of the need for the drugs used for treatment of many diseases, it was found that they leave an adverse effect on non-target site, such as water, soil, air, health and others. Therefore, they should be used and dealt in a scientific way to reduce as much as possible of their negative effects, by preventing drugs using randomly from general public, reducing distribution of physician free samples, separation of domestic waste, sewage recycling, improvement sewage infrastructure, public awareness, nutrition and health maintenance, drugs alternatives and research development.

Locally amoxicillin, ibuprofen, and caffeine are used in pharmaceutical manufacturing products for human and veterinary sector, whether used through physician prescription or by the person himself, this is clear from my reviews of many pharmacies and Palestinian ministry of health.

This research aims to study the kinetics and thermodynamics adsorption of the target pharmaceuticals (amoxicillin, ibuprofen and caffeine) using agricultural soil. From the study of adsorption, this will lead to available information about the possibility of those pharmaceuticals to groundwater

\section{Experimental}

\subsection{Chemicals and reagents}

Amoxicillin, ibuprofen and caffeine of pure substances were obtained from Alfamox (Teofarman, Italy). Acetonitrile and methanol were purchased from Merck (Darmstadt, Germany). 
Water was purified and deionized by a SolPure-7 water purification system. Boric acid, sodium hydroxide and glacial acetic acid of analytical reagent grade were obtained from Aldrich, USA.

Borate buffer was prepared by mixing $100 \mathrm{~mL}$ of $0.1 \mathrm{~mol} / \mathrm{L}$ solution of boric acid with $100 \mathrm{~mL}$ of distilled water and adjusting to $\mathrm{pH}=7$ with $0.05 \mathrm{~mol} / \mathrm{L}$ solution of sodium hydroxide. AccQ-Fluoro reagent (purchased from Waters, USA) at the concentration of $0.25 \mathrm{mmol} / \mathrm{L}$ was prepared by transferring $0.05 \mathrm{~mL}$ of AccQ-Fluro reagent kit ( $5 \mathrm{mmol} / \mathrm{L})$ into a $1.0 \mathrm{~mL}$ volumetric flask and diluting to the mark with acetonitrile.

The HPLC system (Water USA) equipped with a 2475 fluorescent detector, a 2489 spectrophotometric detector, model 515 isocratic pump, a Rheodyne valve with a $20 \mu \mathrm{L}$ loop and Millenium software for collecting data was used. Chromatographic analysis performed on a Lichrosphere 100 RP-C18 (125 mm x $4 \mathrm{~mm}, 5 \mu \mathrm{m}$ particle size) column from Merck at $25^{\circ} \mathrm{C}$.

A mixture of acetonitrile, acetic acid and deionized water $(67: 1: 32, v: v: v)$ was applied as mobile phase at an isocratic elution with a flow program, from $1.0 \mathrm{~mL} / \mathrm{min}$ initially to $4 \mathrm{~min}$, then increased to $3 \mathrm{~mL} / \mathrm{min}$ from 4 to $8 \mathrm{~min}$. Measurements were made using fluorescence detection at an excitation wavelength of $245 \mathrm{~nm}$ and at an emission of $368 \mathrm{~nm}$ and using UV detection for control at $245 \mathrm{~nm}$.

\subsection{Preparation of calibration curves}

Standard working solutions were prepared individually in mobile phase for of $1000 \mathrm{mg} / \mathrm{L}$ of each of the pharmaceuticals in a $1.0 \mathrm{~L}$ volumetric flask. Aliquots from each working solution were combined and diluted with mobile phase to yield a solution concentration of $5,10,20,30$ and $40 \mathrm{mg} / \mathrm{L}$. To each flask, $0.1 \mathrm{~mL}$ of AccQ-Fluor reagent was added and allowed to stand for $30 \mathrm{~min}$. The resulting solutions were subjected to HPLC analysis. Studies on the stability of the analytes in standard working solution showed that there were no decomposition products in the chromatogram or difference in areas during analytical procedure, even after storage for four days at $+4^{\circ} \mathrm{C}$.

\subsection{Soil analysis}

The soil sample was collected from a field far away from those mentioned companies from an area of $1000 \mathrm{~m}^{2}$ and a depth of $20 \mathrm{~cm}$. The sample was sieved in $2.0 \mathrm{~mm}$ sieve, and dried at $105{ }^{\circ} \mathrm{C}$, before any treatment with pharmaceuticals. Several tests were conducted on the soil sample as shown in Table 1.

Table 1. Soil specific gravity, $\mathrm{pH}$, texture, and moisture for soil before pollution.

\begin{tabular}{ll} 
pollution. & Result \\
\hline Soil properties & 2.34 \\
ppecific Gravity & 7.14 \\
Clay value & 41 \\
Silt (\%) & 71 \\
Moisture content (\%) & 29 \\
Organic Carbon (\%) & 7.34 \\
Organic Matter (\%) & 10.36 \\
\hline
\end{tabular}

\subsection{Kinetics and thermodynamics study}

\subsubsection{Surface area measurement}

Soils are made of mineral grains. The grain size distribution of a soil determines the governing particle level forces, inter particle packing. Clay minerals results from weathering in aqueous environments.

It is well known that surface phenomena are important factors influencing the behavior of fine-grained soils. Clay mineralogy, cation exchange capacity, surface area, and clay fraction are all important factors. Surface area can exhibit a significant influence on many physical and chemical properties of fine-grained soils. The term "Specific Surface Area" (SSA) refers to the area/unit mass of soil and is usually expressed as $\mathrm{m}^{2} / \mathrm{g}$. The measurement of external surface areas by the adsorption of simple molecules, such as nitrogen at low temperatures, with surface areas being derived from adsorption isotherm data and the application of BET theory [8], was applied. The surface area was found to be $340 \mathrm{~m}^{2} / \mathrm{g}$ and the shape of grain size is shown in Figure 1.

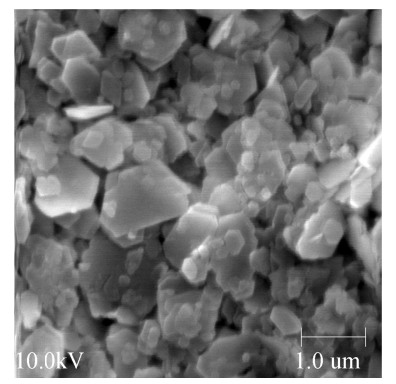

Figure 1. SEM for the shape of particle grains for the soil used as a sorbent.

\subsubsection{Adsorption experiments}

As mentioned above a stock solution of $500 \mathrm{mg} / \mathrm{L}$ of the three pharmaceuticals were prepared in distilled water and diluted to the desired concentrations for the whole desired studies. Batch adsorption experiments were carried out to study the effect of contact time, $\mathrm{pH}$, dosage effect, temperature effect and both kinetics and thermodynamics study for the three drugs. The batch experiments were done in $100 \mathrm{~mL}$ Erlenmeyer flasks included $50 \mathrm{~mL}$ of drugs solution with same concentration of $50 \mathrm{mg} / \mathrm{L}$ for each one and $1.0 \mathrm{~g}$ of soil as sorbent. The soil suspension was continuously mixed by shaking using a thermo stated shaker bath (BS. II digital, JEI. $\mathrm{TECH}$, Korea) and equilibrated for $24 \mathrm{~h}$ at room temperature of $25 \pm 1{ }^{\circ} \mathrm{C}$ to determine equilibrium concentrations. The contents were then centrifuge at $6708 \mathrm{~g}$ for $15 \mathrm{~min}$ to separate solid and aqueous phase. The $\mathrm{pH}$ values were adjusted by $0.1 \mathrm{~N} \mathrm{HCl}$ and $\mathrm{NaOH}$ in the range between 1 to 12 . Solution temperatures were set between 15 to $45^{\circ} \mathrm{C}$ to understand the temperature influence on adsorption process. Other studied parameters were the initial sorbent and adsorbent concentration and solution volume to find out their effects on adsorption process by varying them between $10-50 \mathrm{mg} / \mathrm{L}$ and $0.5-2.5 \mathrm{~g}$, respectively. 1.

The adsorption capacity of the drugs is shown in Equation

$q_{e}(m g / g)=\frac{\left(c_{0}-C_{e}\right) v}{m}$

where $\mathrm{C}_{0}$ and $\mathrm{C}_{\mathrm{e}}(\mathrm{mg} / \mathrm{L})$ are the liquid-phase concentrations of drugs initially and at equilibrium, respectively. $v$ is the volume of the solution (L) and $\mathrm{m}$ is the mass of dry adsorbent used (g). The data were fitted to Langmuir and Freundlich isotherms to evaluate the adsorption parameters.

\subsubsection{Adsorption isotherm}

The equilibrium distribution of drugs in the solution is important factor to determine the maximum of sorption capability.

\subsubsection{Langmuir equation}

It assumes a mono layer adsorption onto a uniform adsorbent surface with energetically identical sorption sites 
[9]. The linear form of Langmuir isotherm equation is given by Equation 2.

$$
\frac{C_{e}}{q_{e}}=\frac{1}{b q_{0}}+\frac{C_{e}}{q_{0}}
$$

where $\mathrm{C}_{\mathrm{e}}$ is the equilibrium concentration of the adsorbate $(\mathrm{mg} / \mathrm{L}), \mathrm{q}_{\mathrm{e}}$ is the amount of adsorbate per unit mass of adsorbent $(\mathrm{mg} / \mathrm{g}), \mathrm{q}_{0}$ and $\mathrm{b}$ are Langmuir constants related to adsorption capacity and rate of adsorption, respectively.

\subsubsection{Freundlich equation}

It describes equilibrium on heterogeneous surfaces and hence does not assume mono layer capacity [9]. The wellknown logarithmic form of the Freundlich isotherm is given by Equation 3.

$\log q_{e}=\log K_{f}+\left(\frac{1}{n}\right) \log C_{e}$

where $\mathrm{C}_{\mathrm{e}}$ is the equilibrium concentration of the adsorbate $(\mathrm{mg} / \mathrm{L})$, qe is the amount of adsorbate per unit mass of adsorbent $(\mathrm{mg} / \mathrm{g}), \mathrm{K}_{\mathrm{f}}$ and $\mathrm{n}$ are Freundlich constants with $n$ giving an indication of how favorable the adsorption process is. $\mathrm{K}_{\mathrm{f}}((\mathrm{mg} / \mathrm{g})(\mathrm{L} / \mathrm{mg}) 1 / n)$ is related with adsorption capacity of the adsorbent. The slope $(1 / n)$ ranging between 0 and 1 is a measure of surface heterogeneity, becoming more heterogeneous as its value gets closer to zero [10]. A value for $(n)$ below one indicates a normal Langmuir isotherm, while $(n)$ above one is indicative of efficient adsorption [11].

\subsubsection{Kinetics experiments}

Removal process can be explained by using several kinetics models. In this study both the order of the rate and the rate constants can be determined from those models. Those constants are significant for designing an effective process. In this study we used the first and pseudo second order models [12].

\subsubsection{First order kinetics model}

The simple form of first order model by applying the boundary conditions, $\mathrm{qt}=0$ at $\mathrm{t}=0$ and $\mathrm{qt}=\mathrm{qt}$ at $\mathrm{t}=\mathrm{t}$, is shown in Equation 4.

$$
\ln \left(q_{e}-q_{t}\right)=\ln q_{e}-k_{1} t
$$

where $\mathrm{k}_{1}$ is the rate constant, $\mathrm{q}_{\mathrm{e}}$ is the drug equilibrium concentration $(\mathrm{mg} / \mathrm{g}) ; \mathrm{q}_{\mathrm{t}}(\mathrm{mg} / \mathrm{g})$ is the amount of adsorbed drugs at any time $t(\mathrm{~min})$.

\subsubsection{Pseudo second order model}

The general form of the model is given as Equation 5.

$$
\frac{d q}{d t}=k_{2}\left(q_{e}-q_{t}\right)^{2}
$$

by integration and linearization of Equation 5 gives

$$
\frac{t}{q_{t}}=\frac{1}{k_{2} q_{e}^{2}}+\frac{1}{q_{e}} t
$$

in which, $\mathrm{k}_{2}$ is the equilibrium rate constant (g/mg.min) of pseudo-second-order chemical sorptin; $\mathrm{q}_{\mathrm{e}}$ is the amount of adsorption sorbed at equilibrium (mg/g); $\mathrm{q}_{\mathrm{t}}$ is the amount of adsorbate sorbed at $t(\mathrm{~min})$. The straight line plots of $\left(\mathrm{t} / \mathrm{q}_{\mathrm{t}}\right) \mathrm{vs} \mathrm{t}$ have been tested to obtain rate parameters [12].

Adsorption kinetics is usually controlled by different mechanisms of which the most general are the diffusion mechanisms which can be explained by intraparticle diffusion model proposed by Weber and Morris. Intra-particle diffusion model can be expressed as [13],

$\mathrm{q}_{\mathrm{t}}=\mathrm{k}_{\mathrm{i}} \mathrm{t}^{0.5}+\mathrm{A}$

where $\mathrm{k}_{\mathrm{i}}$ is the intraparticle diffusion constant and the intercept A reflects the boundary layer effects. The value of $\mathrm{k}_{\mathrm{i}}$ will be calculated from the slope of plotting $\mathrm{q}_{\mathrm{t}} v s \mathrm{t}^{0.5}$.

\section{Results and discussions}

\subsection{Soil tests}

Samples of red soil were analyzed in order to evaluate the soil texture, moisture, $\mathrm{pH}$ value, and specific gravity. Table 1 shows the results obtained from these tests. From the table above it was noticed that the clay percentage is larger than the slit, and both organic carbon and organic matter are high which increase the adsorption capacity of drugs.

\subsection{Effect of contact time}

Experiments were conducted for various time intervals to determine duration required to reach adsorption equilibrium (Figure 2). Adsorption increased with increasing contact time for all pharmaceutical solutions, due to a large number of vacant surface sites are available for adsorption during initial stage, after a while remaining vacant surface sites are very difficult to be occupied because of the repulsive forces between solute molecules in solid and bulk phases [14].

Removal of amoxicillin, ibuprofen and caffeine were 88,82 and $72 \%$, respectively. Adsorption appeared to be governed by two transport processes. During first stage, during first stage, the drugs were rapidly adsorbed for the first two hours. In the second stage, slower migration of the drugs to less accessible sites. Slow uptake of adsorbates and establishment of equilibrium over a long period indicates strong chemical binding of adsorbates with adsorbent $[15,16]$. The study showed that the concentrations of ibuprofen, amoxicillin in the supernatant are decreased with increasing in their adsorption on soil for the first hour, then started to decrease in their adsorption due to its starting degradation, for this reason it's written on the medicine must be kept cool place [17].

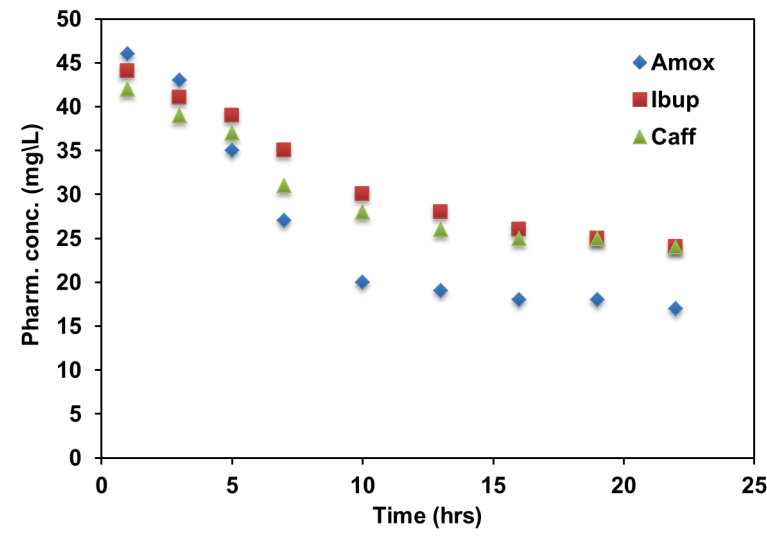

Figure 2. Effect of contact time on the removal of pharmaceuticals by soil at (initial conc. $=50 \mathrm{mg} / \mathrm{L}$, initial $\mathrm{pH}=4$, temperature $=25^{\circ} \mathrm{C}$ and solid/liquid ratio $=1.0 \mathrm{~g} / 50 \mathrm{~mL}$ ). 


\subsection{Effect of adsorbent dosage}

An increase in adsorbent dosage increased percentage removal of pharmaceuticals. In this study various weights of $0.5,0.7,0.9,1.2,1.5,2.0$ and $2.5 \mathrm{~g}$ of soil were used in the presence of $50 \mathrm{mg} / \mathrm{L}$ of each drug. The increase of removal of drugs from solution with increasing dosage can be attributed to the increase number of available sites in the soil [18].

From Figure 3 it looks like all drugs showed the same behavior of removal with the order of Amoxicillin> Ibuprofen> Caffeine with percentage exceeding $90 \%$ in case of amoxicillin at $2.5 \mathrm{mg} / \mathrm{L}$ dosage.

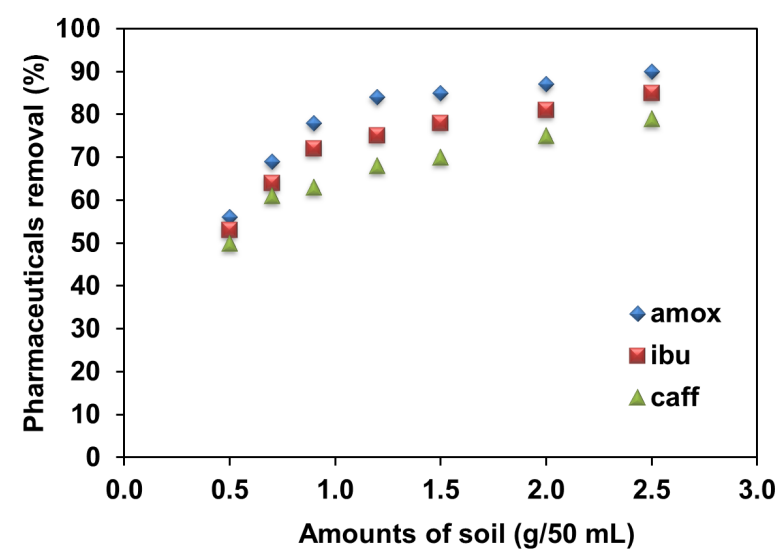

Figure 3. Effect of adsorbent dosage on pharmaceuticals removal soil at (initial conc. $=50 \mathrm{mg} / \mathrm{L}$, initial $\mathrm{pH}=4$, temperature $=25^{\circ} \mathrm{C}$ and contact time $=$ $120 \mathrm{~min})$.

\subsection{Effect of $\mathrm{pH}$}

At a $\mathrm{pH}$ value between $\mathrm{pK}_{\mathrm{a}}$ values of compounds, the drugs exist predominantly as neutral species. Nature of solid surface, like hydrophobic or hydrophilic, and electrical interaction, play an important role in adsorption kinetics of contaminants at solid liquid interface. In this study, a range of $\mathrm{pH}$ varies from 1.5 to 12 were taken and the results are shown in Figure 4.

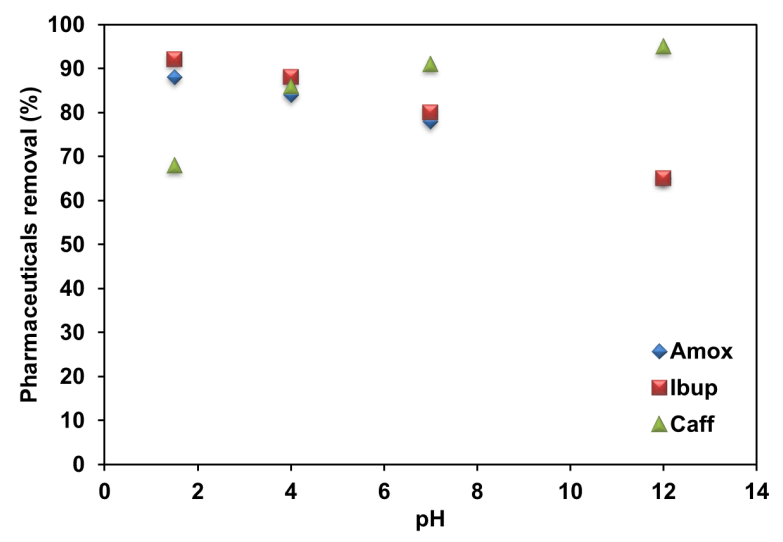

Figure 4. Effect of $\mathrm{pH}$ on to the removal of pharmaceuticals by soil at (initial conc. $=50 \mathrm{mg} / \mathrm{L}$, temperature $=25{ }^{\circ} \mathrm{C}$, contact time $=120 \mathrm{~min}$ and solid/liquid ratio $=1.0 \mathrm{~g} / 50 \mathrm{~mL}$ ).

The adsorption and hydrolysis of the selected pharmaceuticals was influenced by $\mathrm{pH}$ and time, as clearly seen in Figure 4. The effect of $\mathrm{pH}$ on amoxicillin hydrolysis and soil adsorption was the highest amoxicillin adsorption at $\mathrm{pH}$ acidic and alkaline conditions with more stable over the $\mathrm{pH}$ range 4.07.0. This may be due to two facts, the first is the presence of large quantities of $\mathrm{OH}^{-}$ions on the catalysis surface as well as in the reaction medium favors the formation of $\mathrm{OH} \bullet$ radical.
Second is the hydrolysis of these antibiotics since instability of $\beta$-lactam ring at high $\mathrm{pH}$ [13], but its hydrolysis didn't affected at neutral $\mathrm{pH}$.

The study showed that the soil adsorption efficiency of ibuprofen was more efficient under acidic at $\mathrm{pH}$ (1.5 and 4.0) and neutral condition than that in alkaline media as shown in Figure 3. This due to that it consists of hydrophilic and hydrophobic feature, and has dipolar nature of its functional group, with $\mathrm{pK}_{\mathrm{a}}$ value of 4.91, so the carboxyl group of ibuprofen should be at least partly protonated leading to a sorption onto soil particles. While the maximum hydrolysis of ibuprofen was observed in the $\mathrm{pH}$ range of 7-12, due to the presence carboxylic group in its structure, this has been demonstrated in several studies [16-19].

The results also, showed that the lowest of caffeine soil adsorption concentration was at acidic conditions of $\mathrm{pH}=1.5$, 4.0 , and increased at alkaline $\mathrm{pH}=12$, and this is due to caffeine is an acidic compound and dissolves in acidic media [20], and tend to more binding with carboxylic group at alkaline condition.

\subsection{The effect of temperature on (amoxicillin, ibuprofen, and caffeine)-soil adsorption}

The effect of temperature on the adsorption of pharmaceuticals was studied in the range of $15-45{ }^{\circ} \mathrm{C}$ and shown in Figure 5 . As shown from Figure 5, there is a slight increase in adsorption in both amoxicillin and Ibuprofen and a decrease in removal of caffeine.

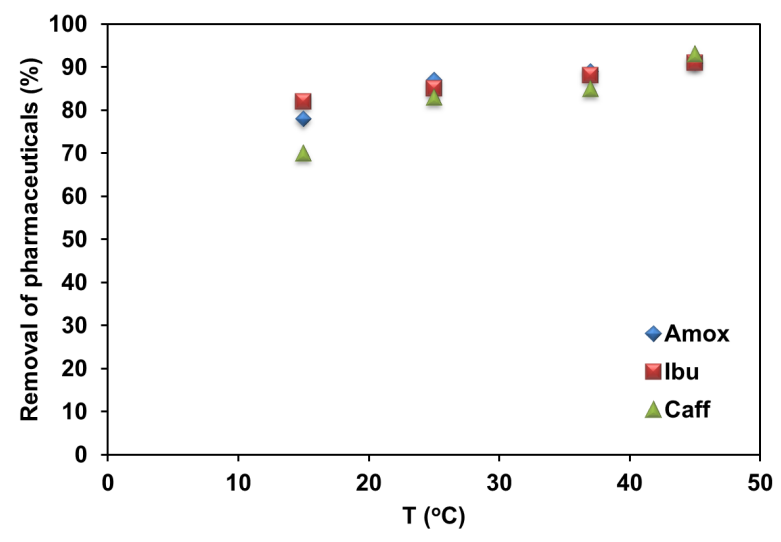

Figure 5. Effect of temperature on pharmaceuticals removal by soil at (initial conc. $=50 \mathrm{mg} / \mathrm{L}$, initial $\mathrm{pH}=4$, contact time $=120 \mathrm{~min}$ and solid/liquid ratio $=1.0 \mathrm{~g} / 50 \mathrm{~mL}$ ).

To clarify the extent of the impact of temperature on the adsorption of drugs on the soil, the degradation of the selected pharmaceuticals was also influenced by microbial activities, oxygen status in the soil, soil type and compound characteristics. While the more decreasing of soil adsorption for caffeine with increasing temperature because it considered as hydrophilic compound and dissolves in water.

\subsection{Adsorption isotherms}

In this study both Langmuir and Freundlich isotherm models were used to describe the relationship between the pharmaceuticals adsorbed and its equilibrium concentration in solution at $25{ }^{\circ} \mathrm{C}$. Adsorption isotherms are shown in Figure 6 and 7. The fittings were investigated by plotting $\mathrm{C}_{\mathrm{e}} / \mathrm{q}_{\mathrm{e}}$ vs $\mathrm{C}_{\mathrm{e}}$ for Langmuir and $\log \mathrm{C}_{\mathrm{e}} v s \log \mathrm{q}_{\mathrm{e}}$ for Fruindlich.

Freundlich adsorption equation is perhaps the most widely used mathematical description of adsorption in aqueous systems, while the Langmuir adsorption isotherm is commonly applied to monolayer chemisorption of gases. 


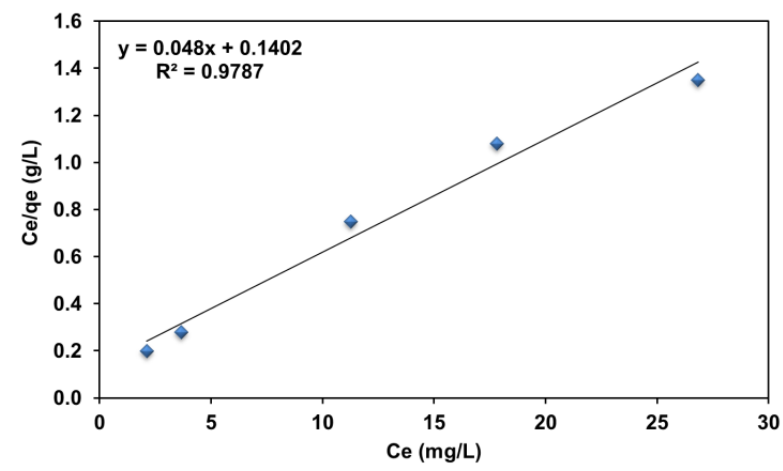

(a)

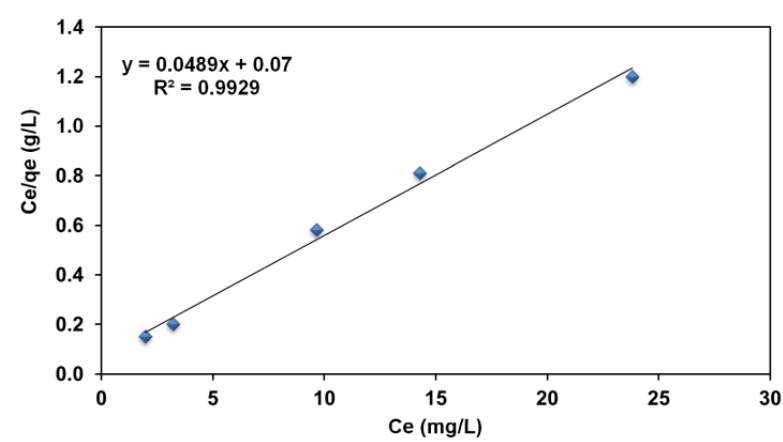

(b)

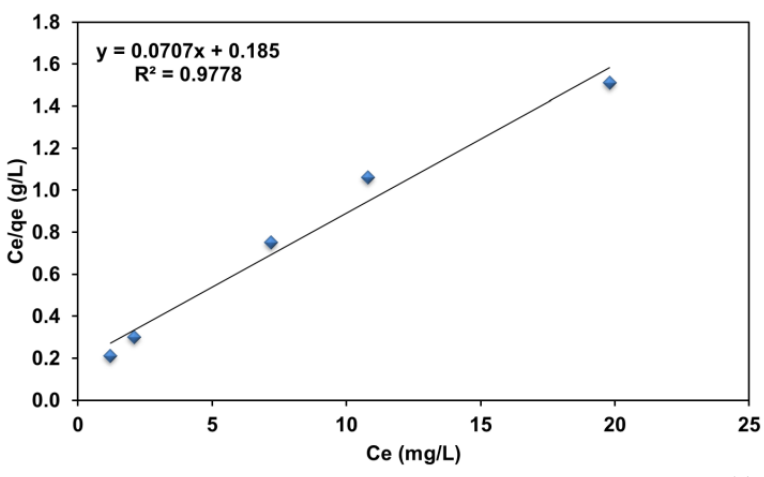

(c)

Figure 6. Langmuir plot for pharmaceuticals adsorption onto soil at $\mathrm{T}=25$ ${ }^{\circ} \mathrm{C}, \mathrm{pH}=4$ and solid/liquid ratio $1.0 \mathrm{~g} / 50 \mathrm{~mL}$ for a) amoxicillin b) ibuprofen c) caffeine.

This isotherm is mainly applied when no strong adsorption is expected and when the adsorption surface is uniform.

To apply the Freundlich Equation on our work various concentrations of pharmaceuticals ranging between $5-50 \mathrm{mg} / \mathrm{L}$ were adsorbed at constant weights of $1.0 \mathrm{~g}$ of soil after $2 \mathrm{hrs}$ of adsorption. The isotherm equilibrium results are shown in Table 2.

Table 2. Langmuir and Freundlich isotherm model parameters and correlation coefficient of pharmaceuticals adsorption.

\begin{tabular}{|c|c|c|c|c|c|c|}
\hline \multirow{2}{*}{$\begin{array}{l}\text { Isotherm } \\
\text { Adsorbate }\end{array}$} & \multicolumn{3}{|c|}{ Langmuir parameters } & \multicolumn{3}{|c|}{ Freundlich parameters } \\
\hline & $\begin{array}{l}q_{0} \\
(\mathrm{mg} / \mathrm{g})\end{array}$ & $\begin{array}{l}\text { B } \\
\text { (L/mg) }\end{array}$ & $\mathbf{R}^{2}$ & $\begin{array}{l}\mathrm{K}_{\mathrm{f}} \\
\left.((\mathrm{mg} / \mathrm{g}) \mathrm{L} / \mathrm{mg})^{1 / \mathrm{n}}\right)\end{array}$ & $\mathbf{n}$ & $\mathbf{R}^{2}$ \\
\hline Amoxicillin & 20.88 & 0.34 & 0.972 & 0.107 & 1.26 & 0.997 \\
\hline Ibuprofen & 20.44 & 0.70 & 0.991 & 0.080 & 1.15 & 0.996 \\
\hline Caffaeine & 14.10 & 0.38 & 0.977 & 0.120 & 4.49 & 0.963 \\
\hline
\end{tabular}

Both the Freundlich and Langmuir adsorption isotherms showed linear relationship results as shown in Figure 6 and 7. For the Freundlich and Langmuir adsorption isotherms, the $\mathrm{R}^{2}$ for the Freundlich adsorption isotherms is closer to 1 more than that in Langmuir adsorption isotherms. The $\mathrm{n}$ values for all the drugs were larger than 1 and this implies stronger interaction between the adsorbate and the adsorbent. The $\mathrm{k}$ values for all the drugs were lower than 1 which indicate that the adsorption capacities were low, and it leaves the soil quickly due to the small surface area of soil [18,21,22]. Generally, higher $\mathrm{K}_{\mathrm{f}}$ values were associated with soil with higher OM content. Our results of ibuprofen agree with previous studies [21,22].

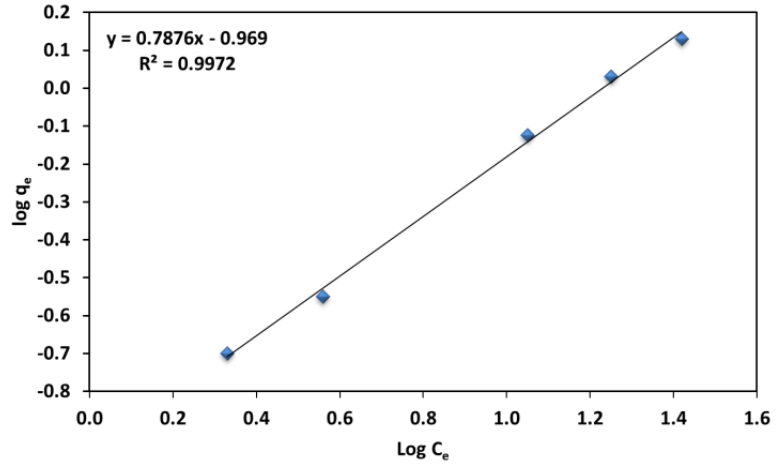

(a)

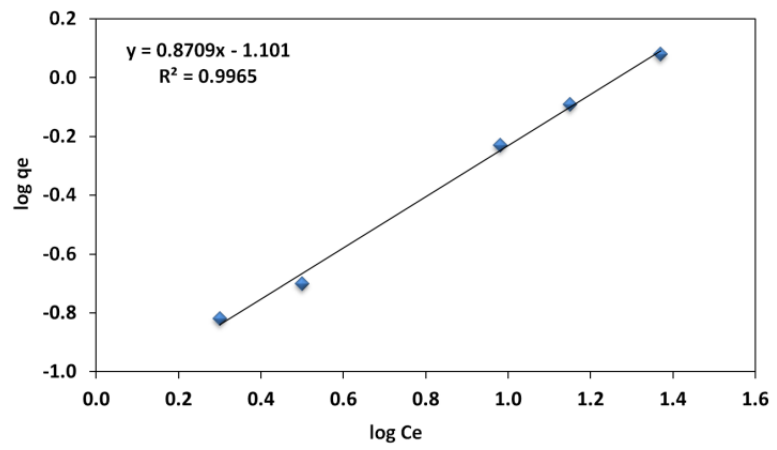

(b)

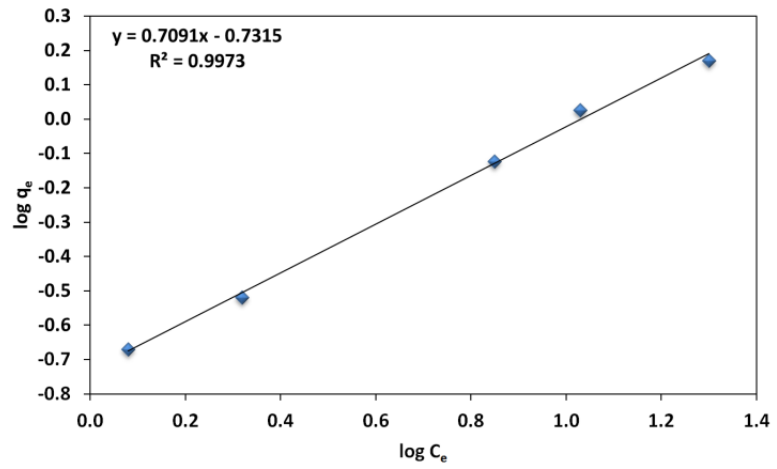

(c)

Figure 7. Freundlich plot for pharmaceuticals adsorption onto soil at $\mathrm{T}=25$ ${ }^{\circ} \mathrm{C}$. $\mathrm{pH}=4$ and solid/liquid ratio $1.0 \mathrm{~g} / 50 \mathrm{~mL}$ for a) amoxicillin b) Ibuprofen c) caffaeine.

\subsection{Kinetics of pharmaceuticals adsorption}

In order to investigate the mechanism of pharmaceuticals adsorption process on soil, the pseudo-first-order kinetic model, the pseudo-second- order kinetic model and the intraparticle diffusion model were all used to test the experimental data. The results are shown in Figure 8-10. The correlation coefficients and other parameters calculated for the pseudofirst-order model, pseudo-second-order model and the intraparticle-diffusion kinetics are listed in Table 3 and 4. 


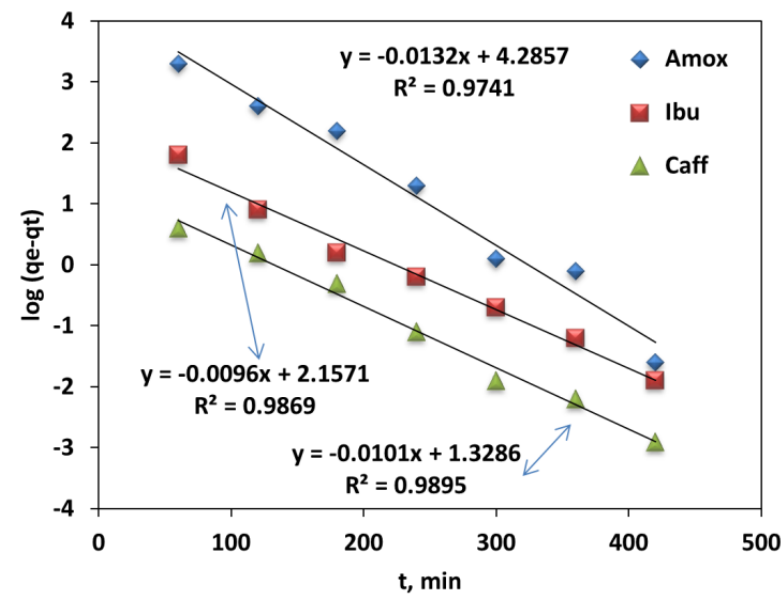

Figure 8. Kinetics of pharmaceuticals removal according to the pseudo-firstorder model by soil at initial concentration of $50 \mathrm{mg} / \mathrm{L}, \mathrm{pH}=4, \mathrm{~T}=25{ }^{\circ} \mathrm{C}$ and solid/liquid ratio $=1.0 \mathrm{~g} / 50 \mathrm{~mL}$

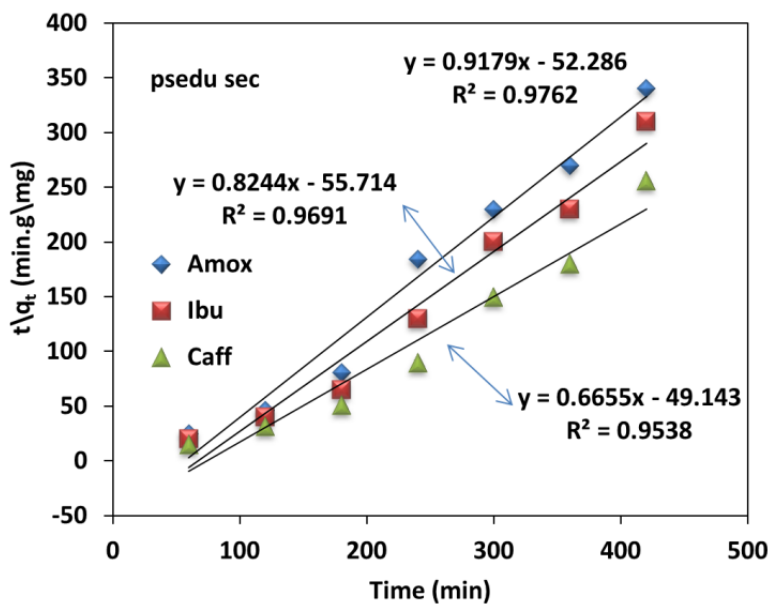

Figure 9. Kinetics of pharmaceuticals removal according to the pseudosecond-order model by soil at initial concentration $50 \mathrm{mg} / \mathrm{L}, \mathrm{pH}=4, \mathrm{~T}=25$ ${ }^{\circ} \mathrm{C}$, and solid/liquid ratio $=1.0 \mathrm{~g} / 50 \mathrm{~mL}$.

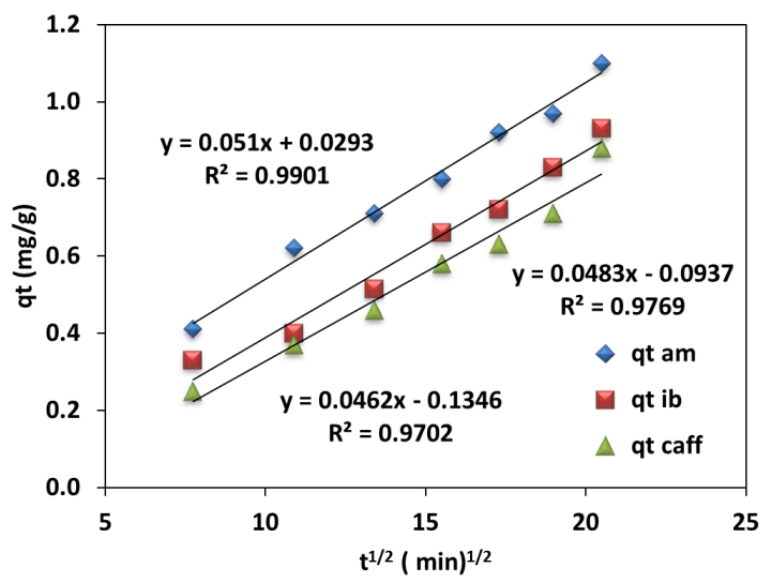

Figure 10. Kinetics of pharmaceuticals removal according to the intraparticle diffusion model by soil at initial concentration $50 \mathrm{mg} / \mathrm{L}, \mathrm{pH}=4$, $\mathrm{T}=25{ }^{\circ} \mathrm{C}$ and solid/liquid ratio $=1.0 \mathrm{~g} / 50 \mathrm{~mL}$
For the intra-particle-diffusion the straight lines did not pass through the origin, this indicates that the rate is limited by mass transfer across the boundary layer and the mechanism of removal of those pharmaceuticals is complex and both the surface adsorption and intra-particle diffusion may contribute to the rate-determining step [23]. The results are shown in Figure 10 and Table 4.

Table 3. Pseudo-first order and pseudo-second order kinetic model parameters for pharmaceuticals adsorption onto soil.

\begin{tabular}{|c|c|c|c|c|c|c|}
\hline \multirow[t]{2}{*}{ Adsorbate } & \multicolumn{3}{|c|}{$\begin{array}{l}\text { Pseudo-first order } \\
\text { parameters }\end{array}$} & \multicolumn{3}{|c|}{$\begin{array}{l}\text { Pseudo-second order } \\
\text { parameters }\end{array}$} \\
\hline & $\begin{array}{l}\mathrm{K}_{1} \\
(1 / \mathrm{min})\end{array}$ & $\begin{array}{l}q_{e} \\
\text { (Calc.) }\end{array}$ & $\mathbf{R}^{2}$ & $\begin{array}{l}K_{2} \\
\text { (g/mg.min) }\end{array}$ & $\begin{array}{l}q_{\mathrm{e}} \\
\text { (Calc.) }\end{array}$ & $\mathbf{R}^{2}$ \\
\hline Amoxicillin & 0.0303 & 19054 & 0.974 & 0.0175 & 1.09 & 0.976 \\
\hline Ibuprofen & 0.0221 & 141 & 0.986 & 0.0128 & 1.21 & 0.969 \\
\hline Caffaeine & 0.0132 & 21 & 0.989 & 0.0135 & 1.53 & 0.953 \\
\hline
\end{tabular}

Table 4. Intra-particle diffusion kinetic model parameters for pharmaceuticals adsorption onto soil.

\begin{tabular}{llll}
\hline Adsorbent & $\mathbf{K}_{\mathbf{p}}\left(\mathbf{m g} / \mathbf{g} \mathbf{~ m i n}^{\mathbf{1} / \mathbf{2}}\right)$ & $\mathbf{A}$ & $\mathbf{R}^{\mathbf{2}}$ \\
\hline Amoxicillin & 0.051 & 0.027 & 0.990 \\
Ibuprofen & 0.048 & -0.093 & 0.976 \\
Caffaeine & 0.046 & -0.134 & 0.970 \\
\hline
\end{tabular}

\subsection{Adsorption thermodynamics}

The thermodynamic parameters including changes in standard enthalpy $\left(\Delta \mathrm{H}^{\circ}\right)$, standard entropy $\left(\Delta \mathrm{S}^{\circ}\right)$ and standard free energy $\left(\Delta G^{\circ}\right)$ of adsorption can be calculated by means of Equations 8-10 [24].

$\ln k_{d}=\frac{\Delta S^{\circ}}{R}-\frac{\Delta H^{\circ}}{R} \frac{1}{T}$

where $\mathrm{R}(8.314 \mathrm{~J} / \mathrm{mol} . \mathrm{K})$ is the universal gas constant, $\mathrm{T}(\mathrm{K})$ is the absolute solution temperature and $K_{d}$ is the distribution coefficient which can be calculated as:

$\mathrm{K}_{\mathrm{d}}=\mathrm{C}_{\mathrm{Ae}} / \mathrm{C}_{\mathrm{e}}$

where $\mathrm{C}_{\mathrm{Ae}}(\mathrm{mg} / \mathrm{L})$ is the amount adsorbed on solid at equilibrium and $\mathrm{C}_{\mathrm{e}}(\mathrm{mg} / \mathrm{L})$ is the equilibrium concentration. $\Delta \mathrm{G}^{\circ}$ can be calculated using the relation below:

$\Delta G^{0}=-R T \ln K_{d}$

The values of $\Delta \mathrm{H}^{\circ}$ and $\Delta \mathrm{S}^{\circ}$ are calculated from the slopes and intercepts of the linear variation of $\ln K_{d}$ with reciprocal temperature $(1 / \mathrm{T})$ Figure 11 . The obtained thermodynamic values are given in Table 5 .

Table 5. The values of thermodynamics of adsorption of pharmaceuticals on soil.

\begin{tabular}{|c|c|c|c|c|c|c|}
\hline \multirow{2}{*}{ Pharmaceuticals } & \multirow{2}{*}{$\begin{array}{l}\Delta \mathrm{H}^{\mathrm{O}} \\
(\mathrm{KJ} / \mathrm{mol})\end{array}$} & \multirow{2}{*}{$\begin{array}{l}\Delta S^{\mathbf{0}} \\
(\mathrm{J} / \mathrm{mol} \mathrm{K})\end{array}$} & \multicolumn{4}{|c|}{$\Delta \mathrm{G}^{\mathbf{0}}(\mathrm{KJ} / \mathrm{mol})$} \\
\hline & & & $285 \mathrm{~K}$ & $294 \mathrm{~K}$ & $312 \mathrm{~K}$ & $322 \mathrm{~K}$ \\
\hline Amoxicillin & -19.70 & -0.85 & -2.85 & -2.20 & -1.37 & -0.53 \\
\hline Ibuprofen & -15.07 & -0.66 & -2.08 & -1.54 & -0.70 & -0.40 \\
\hline Caffaeine & -9.97 & -0.44 & -1.42 & -0.86 & -0.51 & -0.13 \\
\hline
\end{tabular}

The negative values of $\Delta \mathrm{G}^{\circ}$ at various temperatures indicated that the adsorption process on soil is spontaneous and the negative values of $\Delta \mathrm{H}^{\circ}$ show that the adsorption is exothermic. Furthermore, the negative value of entropy indicates the affinity of adsorbent material for drugs. Increase in the value of $\Delta \mathrm{G}^{\circ}$ with rise in temperature show that the adsorption is more favorable at lower temperature.

\section{Conclusion}

The adsorption characteristics of Pharmaceuticals in soils and ground water are of great importance environmentally, because such process is associated with the ecotoxicity, degradation, transportation, and bioaccumulation of them in 
the soil environment. Adsorption of ibuprofen, amoxicillin, and caffeine was studied and the following results were obtained:

Amoxicillin and ibuprofen soil adsorption in this study was increased with increasing temperature versus time due to their high solubility of water. The caffeine showed lower adsorption. The effect of $\mathrm{pH}$ showed higher removal of both amoxicillin and ibuprofen in the acidic medium at $\mathrm{pH}=1-4$, while caffeine showed higher adsorption in the basic medium.

All the studied pharmaceuticals followed the Freundlich isotherm with $\mathrm{n}>1$ and caffeine showed about 4.5 which means they have very high interaction with soil. For the kinetic studies they followed the pseudo-second-order model and the thermodynamics parameters showed that the adsorption process on soil was spontaneous and exothermic.

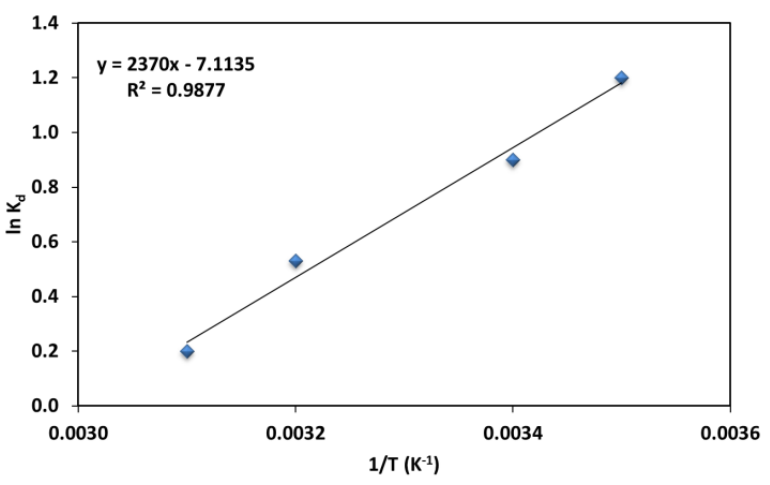

(a)

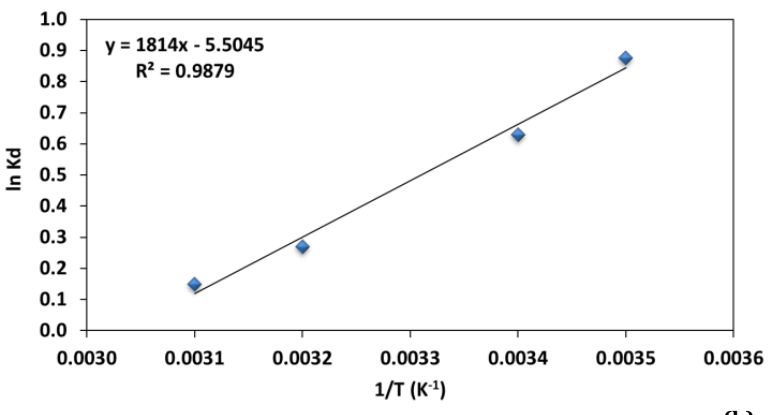

(b)

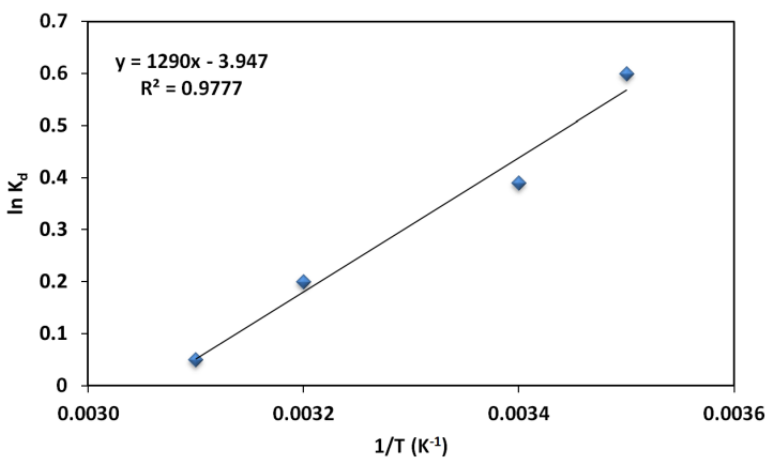

(c)

Figure 11. Plot of $\ln \mathrm{Kd} v s \mathrm{1} / \mathrm{T}$ for $50 \mathrm{mg} / \mathrm{L}$ concentration of a) amoxicillin b) ibuprofen c) caffeine.

\section{Acknowledgements}

I would like to thank the Palestinian Union Universities for helping and supporting this study. I would like to thank Ms. Haleemah Esteetee and Dr. Tamara Renno for the HPLC experiments.

\section{References}

[1]. Dietrich, D. R.; Webb, S. F.; Petry, T. Hot Spot Pollutants: Pharmaceutical in the Environment, Elsevier Academic Press, MA, New York, USA, 2005.

[2]. Kotchen, M.; Kallaos, J.; Wheeler, K.; Wong, C.; Zahller, M. J. Environ Manage. 2009, 90,1476-1482.

[3]. Thompson, A. The fate and removal of pharmaceuticals during sewage treatment, Ph.D. Thesis, Cranfield University, UK, 2005.

[4]. Kummerer, K. Pharmaceutical in the Environment: Sources, Fate, Effect and Risks, $3^{\text {rd }}$ edition, Springer, Berlin, Heidelberg, New York, U. S. A., 2008.

[5]. Karnjanapiboonwong, A.; Suski, J.; Shah, A. A.; Cai, Q.; Morse. A. N.; Anderson, T. A. Water Air Soil Poll. 2011, 216, 257-273.

[6]. Jodeh, S.; Staiti, H.; Haddad, M.; Renno, T.; Zaid, A.; Jaradat, N.; Kharoaf, M. Eur. J. Chem. 2012, 3(4), 480-484.

[7]. Yu, C. P.; Chu, K. H. Chemosphere 2009, 75, 1281-1286.

[8]. Brunauer, S.; Emmett, P. H.; Teller, E. J. Am. Chem. Soc. 1938, 60, 309319.

[9]. AlDuri, B. Adsorption modeling and mass transfer. Use of adsorbents for the removal of pollutants from wastewaters, G. Mckay ed. , CRC press, Boca Ratou, Florida, 1996. pp. 133-173.

[10]. Haghseresht, F.; Lu, G. Q. Energ. Fuel 1998, 12, 1100-1107.

[11]. Fytianos, K.; Voudrias, E.; Kokkalis, E. Chemosphere 2000, 40, 3-6.

[12]. Ugurlu, M.; Gurses, A.; Acikyildiz, M. Micropor. Mesopor. Mat. 2007, 111, 228-235.

[13]. Elmolla, E. S.; Chaudhuri, M. J. Hazard. Mater. 2009, 172, 1476-1481.

[14]. Mali, D. I.; Srivastava, V. C.; Agarwal, N. K. Dyes Pigments 2006, 69, 210-223.

[15]. Adak, A.; Bandyopadhyay, M.; Pal A. Colloid Surface A 2005, 254, 165 171.

[16]. Dwivedi, A.; Gopal, K.; Jain, R. Chem. Eng. J. 2011, 168, 1279-1288.

[17]. Gupta, S.; Pal, A.; Ghosh, P. K.; Bandyopadhyay, M. J. Environ. Sci. Health $A$ 2003, 38, 381-397.

[18]. Zheng, J. P.; Luan, L.; Wang, H. Y.; Yao, K. D. Appl. Clay. Sci. 2007, 36, 297-301.

[19]. Oppel, J.; Broll, G. B.; Loffler, D. C.; Meller, M. D.; Rombke, J. D.; Ternes, T. Sci. Total Environ. 2004, 328, 265-273.

[20]. Lim, L. Y.; Go, M. L. Eur. J. Pharm. Sci. 2000, 10, 17-28.

[21]. Putra, E. K.; Pranowo, R.; Sunarso, J.; Indraswati, N.; Ismadji, S. Water Res. 2009, 43, 2419-2430.

[22]. Sotelo, J. L.; Rodriguez, A.; Alvarez, S.; Garcia, J. Chem. Eng. Res. Des. 2011, 90, 967-974.

[23]. Gregg, S. J.; Singh, K. S. Adsorption surface area and porosity. Academic Press., New York, U. S. A, 1967.

[24]. Tan, I. A.; Ahmad, A. L.; Hameed, B. H. J. Hazard. Mater. 2008, 154 337-346. 